\title{
Weight gain in British first year university students: Is the 'Freshman 15' only an American phenomenon?
}

\author{
C. Cockman, J. O'Reilly and D. D. Mellor \\ Department of Clinical Sciences and Nutrition, University of Chester, Parkgate Road, Chester, CHI 4BJ, UK
}

A systematic search of web-based search engines of the term 'Freshman 15' yields over 98 million results; it refers to the theorised 15 pounds $(6.8 \mathrm{~kg})$ students gain in weight during the first semester of university. There have been a number of studies conducted in the United States (US) investigating the validity of the 'Freshman $15^{,(1)}$. However, it is unclear whether this phenomenon occurs in Britain, as it is thought British universities are less obesogenic than their US counterparts ${ }^{(2)}$. This study investigated changes in weight amongst female British students in their first semester at university.

Height, weight, BMI, waist circumference and fat percentage of first and final year female undergraduate students were measured at both the beginning $(n=88)$ and end $(n=49)$ of the first semester (October 2012 and February 2013 respectively). Subjects also completed a questionnaire regarding dietary habits and lifestyle. Data following assessment of normality was analysed using the appropriate repeated measure ANOVA. Categorical data was analysed by Chi-square test. CH1 4BNJThe departmental research ethics committee undertook ethical review and the study was carried out in accordance with the Declaration of Helskini.

First year students gained a significant amount of weight $2.55 \mathrm{~kg}(p<0.001)$, resulting in an increase in BMI of $0.93 \mathrm{~kg} / \mathrm{m}^{2}(p=0.011)$. This was significantly different to the final year students who whose weight did not change $(p<0.05)$. The effect of this was three individuals moved into a higher risk BMI category, e.g. overweight to obese and $22 \%$ gaining or exceeding the 'freshman 15 ' ( $>6.8 \mathrm{~kg}$ ). The increase in body weight was also accompanied by an increase in body fat percentage $2.67 \%(p=0.011)$. The potential explanatory factors for this weight change were seen through a change in a number of lifestyle factors. A significant reduction was seen in the intake of fruit $(p=0.014)$ with an increase in the intake of processed foods and take-away foods $(p=0.011$ and $(p=<0.001)$, respectively. Additionally, a significant increase was seen in both first years frequency and volume of alcohol consumed ( $p=<0.001$ for both). This was accompanied by a trend suggesting a decrease in the duration, but not frequency of exercise. There were no significant changes in either the body composition, diet and/or lifestyle of the final year students.

This study found the 'Freshman 15' did occur for a substantial minority of first year students. However, a significant weight gain and increase in BMI was measured which on average was about a third of that reported 'Freshman 15'. This suggests the first year of university could be seen as a critical period of where a change in lifestyle can result in significant weight change, this may be of relevance for disease later in life. Potential causative factors for this weight gain could be the result of dietary and lifestyle changes that occur during the transition to university. This study has provided the first attempt to understand the trends in weight gain that occur in British universities. However further research is needed to full assess the extent and health implications of weight change, and how it occurs across a student's time at university, including the possible causative factors.

1. Levitsky DA, Hlabmair CA \& Mrdjenovic G (2004) Int J Obes RElat Metab Disord. 28(1), 1435-1442.

2. Cohen-Cole E \& Fletcher JM (2007) J of Health Econ, 27(5), 1382-1387. 